Article

\title{
Using RNA Interference to Reveal the Function of Chromatin Remodeling Factor ISWI in Temperature Tolerance in Bemisia tabaci Middle East-Asia Minor 1 Cryptic Species
}

\author{
Shun-Xia Ji ${ }^{1}$, Xiao-Di Wang ${ }^{1}$, Xiao-Na Shen ${ }^{1}$, Lin Liang ${ }^{1}$, Wan-Xue Liu ${ }^{1}$, Fang-Hao Wan ${ }^{1,2}$ \\ and Zhi-Chuang $L \ddot{L}{ }^{1, *}$ \\ 1 State Key Laboratory for Biology of Plant Diseases and Insect Pests, Institute of Plant Protection, \\ Chinese Academy of Agricultural Sciences, Beijing 100193, China; 82101172334@caas.cn (S.-X.J.); \\ wxd203741084@163.com (X.-D.W.); naxiaoshen@163.com (X.-N.S.); 13808790897@163.com (L.L.); \\ liuwanxue@caas.cn (W.-X.L.); wanfanghao@caas.cn (F.-H.W.) \\ 2 Agricultural Genome Institute at Shenzhen, Chinese Academy of Agricultural Sciences, \\ Shenzhen 518120, China \\ * Correspondence: lvzhichuang@caas.cn; Tel.: +86-10-8210-9572
}

Received: 26 December 2019; Accepted: 20 January 2020; Published: 10 February 2020

\begin{abstract}
Invasive species often encounter rapid environmental changes during invasions and only the individuals that successfully overcome environmental stresses can colonize and spread. Chromatin remodeling may be essential in environmental adaptation. To assess the functions of imitation switch (ISWI) in invasive Bemisia tabaci Middle East-Asia Minor 1 (MEAM1) cryptic species, we cloned and characterized the MEAM1 BtISWI gene and determined its functions in response to thermal stress. The full-length cDNA of BtISWI was $3712 \mathrm{bp}$, with a $3068 \mathrm{bp}$ open reading frame (ORF) encoding a $118.86 \mathrm{kDa}$ protein. BtISWI mRNA expression was significantly up-regulated after exposure to heat shock or cold shock conditions, indicating that BtISWI expression can be induced by thermal stress. After feeding double-stranded RNA (dsRNA), specifically for BtISWI, resistance to both heat and cold decreased significantly, suggesting that BtISWI may function directly in the thermal tolerance of MEAM1. Moreover, the preferred temperature of MEAM1 adults fed dsRNA was $1.9-3.5^{\circ} \mathrm{C}$ higher than the control groups. Taken together, our findings highlight the importance of epigenetic gene regulation in the thermal response or thermal adaptation of invasive Bemisia tabaci (B. tabaci), and provide a new potential target for establishing sustainable control strategies for B. tabaci.
\end{abstract}

Keywords: Bemisia tabaci; epigenetics; ISWI; RNA interference; temperature preference; thermal stress

\section{Introduction}

Epigenetics is attracting increasing research attention because it has rapid and long-lasting effects on gene expression in response to environmental changes without altering DNA sequences [1,2]. Epigenetic regulation mediates phenotypic changes caused by various stresses in numerous organisms [3]. As invasive species often encounter rapid environmental changes during invasions, only the individuals successfully overcoming environmental stresses will colonize and spread, and they provide an ideal model to investigate how species epigenetically cope with various stressful environments [4-7]. Previous studies have suggested that epigenetic regulation may function directly in environmental adaptation, and may be particularly important for the success of invasive species [8-11].

Adenosine triphosphate (ATP)-dependent chromatin remodeling factors are important components in epigenetic regulation. These factors are multisubunit protein complexes that utilize the 
energy generated from ATP hydrolysis to modulate the access of transcription factors (TFs) and other regulatory proteins to genomic DNA by sliding nucleosomes and increasing chromatin fluidity $[12,13]$. According to the conserved domains, these remodelers were divided into four subfamilies: SWI/SNF (SWItch/Sucrose Non Fermentable), ISWI (Imitation SWItch), INO80 (INOsitol requiring 80), and CHD (Chromo Helicase Domain) [14-16]. INO80 and CHD are large complexes containing many subunits, while the ISWI complexes are relatively small and contain only two, three, or four subunits [17]. In addition, the number of ISWI-containing complexes is unequal in different organisms. Six different functional ISWI complexes have been identified (CHRAC(chromatin accessibility complex), ACF(ATP-utilizing chromatin assembly and remodeling factor), NURF (nucleosome remodeling factor), RSF(remodeling and spacing factor), ToRC (toutatis containg chromatin remodeling complex), and NoRC(nucleolar remodeling complex)) in Drosophila melanogaster [18,19], while seven different ISWI complexes have been described (NURF, ACF, WICH (WSTF-ISWI chromatin remodeling complex), NoRC, CHRAC, RSF, and CERF(CECR2-containing remodeling factor)) in mammals [20].

ISWI-containing protein complexes have multiple roles. For example, research in Drosophila has shown that NURF, a chromatin-remodeling complex that contains ISWI as its ATPase subunit, cooperates with the GAGA factor (GAGA-DBD) to mobilize nucleosomes on the promoter of heat-shock genes and facilitate the binding of heat-shock TFs [21,22]. In yeast, ISWI also played an important role in regulating heat shock genes [23]. Buszewicz et al. [24] found that chromatin remodeling complex and histone deacetylase interacted and both were involved in mediating the heat stress response in Arabidopsis. Genetic studies in Saccharomyces cerevisiae suggested that ISWI complexes are involved in the transcriptional repression of early meiotic genes [25]. Research into plants showed that ISWI ATPase acted as a repressor of at least two flowering pathways [26]. In addition, Collins and co-workers found that ISWI in mammals was required for DNA replication through highly condensed heterochromatin [27].

The whitefly Bemisia tabaci (Gennadius) (Hemiptera: Aleyrodidae) is a globally important pest in agriculture that causes damage to many crops through phloem feeding, transmission of plant viruses, and deposition of honeydew [28]. It is considered to be a species complex that contains at least 36 morphologically indistinguishable species [29-31]. The B. tabaci Middle East-Asia Minor 1 (MEAM1, former biotype B) cryptic species, which was identified sometime in the late 1980s, principally via the trade in ornamentals, has successfully colonized and spread to at least 54 countries [29,32], and its ability to adapt to various environmental temperatures is one of the key reasons for its success [33-35].

Previous studies have shown that exposing whiteflies to thermal stress is accompanied by rapid alteration of gene expression [36-40]. In addition, Lü et al. [41] found that B. tabaci significantly improved its survival rate within two generations after heat shock selection experiments and speculated that this rapid increase in viability may be related to epigenetic regulation. Furthermore, studies on DNA methyltransferases involved in epigenetic regulation indicated that DNA methyltransferase 1 and DNA methyltransferase 3 functioned directly in the temperature tolerance of B. tabaci $[39,42]$. These results implied that a possible explanation for rapidly increased temperature tolerance is the regulatory plasticity of genes mediated by epigenetic mechanisms. While ISWI-containing chromatin remodeling complexes were thought to be related to the rapid acquisition of adaptative traits and thermal resistance, relevant experimental evidence is scarce.

In the present study, we assessed the functions of BtISWI in invasive MEAM1. First, we cloned the full-length cDNA sequence of the MEAM1 BtISWI gene and analyzed its characteristics. Compared with the annotated ISWI from the draft genome of B. tabaci MEAM1 [43], the nucleic acid sequence similarity was $78.18 \%$, and the deduced amino acid sequence similarity was $100 \%$. Second, expression profiles of BtISWI in response to thermal stress were determined. Third, we identified the function of BtISWI in thermal resistance by RNA interference (RNAi). Finally, the temperature preferences of MEAM1 adults after dsRNA feeding were identified. These data will help us to reveal novel functions for the ISWI ATPase in vivo and lay the foundation for further studies aimed at understanding the potential links between chromatin remodeling and thermal plasticity in invasive insects. 


\section{Materials and Methods}

\subsection{Insect Rearing}

The B. tabaci MEAM1 cryptic species used in this study were reared on healthy cotton plants, Gossypium hirsutum (L.) (Zhong No. 287), in insect-proof cages in a greenhouse at $26 \pm 1{ }^{\circ} \mathrm{C}, 50-60 \%$ relative humidity $(\mathrm{RH})$, and a photoperiod of 14:10 h (L:D). The cotton plants were individually grown in $9 \mathrm{~cm}$-diameter pots under the same conditions as the whiteflies.

\subsection{Total RNA Isolation and Reverse Transcription}

Total RNA was isolated from the whiteflies using TRIzol (Invitrogen, Carlsbad, CA, US) according to the manufacturer's instructions. Subsequently, the quality and concentration of RNA were evaluated using a NanoPhotometer ${ }^{\mathrm{TM}}$ P330 (Implen, Munich, Germany) and 1\% agarose gel electrophoresis. The first-strand complementary DNA (cDNA) was generated from $1.0 \mu \mathrm{g}$ RNA using the One-Step gDNA Removal and cDNA Synthesis SuperMix (TransGen, Beijing, China).

\subsection{Cloning and Sequencing of BtISWI}

To identify the BtISWI gene, BLASTP (protein-protein Basic Local Alignment Search Tool) and TBLASTN (search translated nucleotide databases using a protein query) searches of $B$. tabaci MEAM1 genome information [43] were performed using published ISWI protein sequences from Drosophila melanogaster (NP_523719.1), Nilaparvata lugens (XP_022189967.1), and Acyrthosiphon pisum (XP_001945595.1) as queries. According to the sequence obtained above, specific primers were designed (as shown in Table 1). All PCR (Polymerase Chain Reaction) amplifications were carried out using FastPfu DNA Polymerase (TransGen, Beijing, China), and amplified fragments were purified using an AxyPrep $^{\mathrm{TM}}$ DNA Gel Extraction Kit (Axygen, West Orange, NJ, US), then cloned into the pEASY-Blunt Vector (TransGen, Beijing, China) following the manufacturer's instructions and sequenced.

Table 1. Primers used for cDNA cloning, qRT-PCR (Quantitative real time PCR), and dsRNA synthesis.

\begin{tabular}{|c|c|}
\hline Primer & Primer Sequence $\left(5^{\prime}\right.$ to $\left.3^{\prime}\right)$ \\
\hline \multicolumn{2}{|c|}{ Primers for full-length gene amplification } \\
\hline ISWI-F1 & GCTTCAGCCAATATGGCGACT \\
\hline ISWI-R1 & CGGCAGCAGCTTATCAAGAATG \\
\hline ISWI-F2 & GACCTTTCTTGTTGCGTCGTCTC \\
\hline ISWI-R2 & GGCGCTTGATACCTCTCCATTT \\
\hline ISWI-F3 & ACTATTTCCGCAAGTCAGTGGGC \\
\hline ISWI-R3 & GACGACGCATCTCAAGGCTAAA \\
\hline \multicolumn{2}{|c|}{ Primers for real-time quantitative PCR } \\
\hline ISWI-QF & GCAGGTTAGATGGTCAAACTCCCC \\
\hline ISWI-QRR & TTTTCCTCAACAGTATTTTCGGTG \\
\hline $\mathrm{EF} 1-\alpha-\mathrm{F}$ & TAGCCTTGTGCCAATTTCCG \\
\hline $\mathrm{EF} 1-\alpha-\mathrm{R}$ & CCTTCAGCATTACCGTCC \\
\hline$\beta$-tub-F & TGTCAGGAGTAACGACGTGTTTG \\
\hline$\beta$-tub-R & TTCGGGAACGGTAAGTGCTC \\
\hline \multicolumn{2}{|c|}{ Primers for dsRNA synthesis } \\
\hline ISWI-DF & TAATACGACTCACTATAGGGCTCCGATTCACCCTCT \\
\hline ISWI-DR & TAATACGACTCACTATAGGGGTCCCAGTCTCCAGGC \\
\hline
\end{tabular}

\subsection{Bioinformatics Analysis}

Sequence alignments and comparisons of sequence similarity were performed using DNAMAN (version 7.0; LynnonBioSoft, Quebec, QC, Canada). ORF FINDER (http://www.ncbi.nlm.nih.gov/ orffinder/) was used to predict ORFs. The physical and chemical properties of the deduced amino 
acid sequence were predicted using ExPASy (http://web.expasy.org/protparam/). Conserved functional domains were identified with the online CONSERVED DOMAINS database of NCBI (https://www. ncbi.nlm.nih.gov/Structure/cdd/wrpsb.cgi). The three-dimensional structures of the protein domains were produced with SWISS-Model (https://www.swissmodel.expasy.org/) and edited using PyMOL. Multiple protein sequence alignments were performed using ClustalW, and the phylogenetic tree was constructed using the maximum likelihood method based on the Whelan Goldman (WAG) model with 1000 bootstrap replications in MEGA7.0 software [44,45].

\subsection{Real-Time Quantitative PCR}

Quantitative real time PCR (qRT-PCR) was used to analyze the gene expression profile with an ABI 7500 real-time PCR system (Applied Biosystems, Foster City, CA, USA). Total RNA extraction and cDNA synthesis were conducted, as described above. The primers used in this study are listed in Table 1, including two reference genes-beta-1-tubulin ( $\beta$-tub) and elongation factor 1 alpha (EF1- $\alpha)$ - to normalize the mRNA expression levels [46]. Each reaction $(20 \mu \mathrm{L})$ contained $10.0 \mu \mathrm{L}$ qPCR SYBR Green Master Mix (Yeasen, Shanghai, China), $1.0 \mu \mathrm{L}$ cDNA template, $0.4 \mu \mathrm{L}$ of each primer $(10 \mu \mathrm{M})$, and $8.2 \mu \mathrm{L}$ of double distilled $\mathrm{H}_{2} \mathrm{O}$. The PCR procedure was as follows: $95^{\circ} \mathrm{C}$ for $5 \mathrm{~min}$, then 40 cycles of $95^{\circ} \mathrm{C}$ for $10 \mathrm{~s}$ and $60^{\circ} \mathrm{C}$ for $30 \mathrm{~s}$, followed by a melting curve analysis. There were three repetitions for each treatment and control, with 200 adults in each repetition and the ratio of females:males was 1:1. Each repetition was assessed in triplicate (technical replicates).

\subsection{Temperature Stress Treatment}

Based on our previous studies [40,42], we selected $0,12,35$, and $40^{\circ} \mathrm{C}$ for short-term temperature stress treatments. Owing to research found that adult age was associated with different responses to thermal tolerance [47], we standardized adult age using only newly emerged whiteflies that were younger than $3 \mathrm{~h}$. MEAM1 adults were placed together in a $1.5 \mathrm{~mL}$ centrifuge tube, then the tubes were placed in a constant-temperature environment $\left(0,12,35\right.$, and $\left.40^{\circ} \mathrm{C}\right)$ for 1,3 , and $5 \mathrm{~h}$. Adults maintained at $26^{\circ} \mathrm{C}$ served as a control group. After thermal stress treatment, whiteflies were collected immediately for qRT-PCR. Each treatment was biologically replicated three times, with 200 adults in each repetition and the ratio of females:males was 1:1.

\subsection{RNA Interference}

Double-stranded RNA (dsRNA) used in this study was synthesized using the MEGAscript T7 High Yield Transcription Kit (Ambion, Austin, TX, USA) with gene-specific primers (Table 1). Then, the ISWI dsRNA was diluted to $0.4 \mu \mathrm{g} / \mu \mathrm{L}$ in a $10 \%$ sucrose solution for further feeding treatment (for detailed methods, refer to References [42,48]). Simultaneously, we set control groups including untreated whiteflies, those fed with eGFP-specific dsRNA (dseGFP), and those fed with $10 \%$ sucrose. After feeding for $3 \mathrm{~h}$, partial samples were immediately frozen with liquid nitrogen and then stored at $-80^{\circ} \mathrm{C}$ for analyzing the BtISWI mRNA expression level. The rest of the newly emerged MEAM1 adults were collected immediately for thermal tolerance tests or temperature preference behavioral assays.

\subsection{Thermal Tolerance Test after dsRNA Feeding}

For heat resistance, we measured the tolerance times for whiteflies exposed to a high temperature [49-51]. Two whiteflies were placed in a $1.5 \mathrm{~mL}$ centrifuge tube, then the tube was transferred to a constant temperature of $45 \pm 0.2{ }^{\circ} \mathrm{C}$ in a water bath, controlled with a CC-106A temperature controller (Huber Kältemaschinenbau $\mathrm{GmbH}$ ). We measured the interval between the time the tube was placed in the water bath and the time when the whitefly lost control of its body and could not stand autonomously. For cold tolerance, we measured the recovery time following a chill coma induced by cold shock $[50,52]$. MEAM1 adults, placed in tubes, as described above, were exposed to $-5 \pm 0.2^{\circ} \mathrm{C}$ in a refrigeration bath circulator (K6-cc-NR, Huber Kältemaschinenbau GmbH, Offenburg, Germany) for $10 \mathrm{~min}$, and the recovery time was observed at $26 \pm 0.2^{\circ} \mathrm{C}$. Each treatment had four 
biological replicates, with 200 adults in each repetition and the ratio of females:males was $1: 1$. The $45^{\circ} \mathrm{C}$ and $-5^{\circ} \mathrm{C}$ conditions were selected based on pre-experiments showing that these temperatures were the discrimination points for whitefly temperature tolerance [50].

\subsection{Temperature Preference Behavioral Assay}

A temperature control device that can generate a series of thermal gradients was used to assay the temperature preference of MEAM1 adults after dsRNA feeding. The temperature gradient $\left(12-30{ }^{\circ} \mathrm{C}\right)$ was produced in an aluminum block $(30 \mathrm{~cm}$ long $\times 10 \mathrm{~cm}$ wide $\times 1 \mathrm{~cm}$ high $)$ with a slope of $0.72{ }^{\circ} \mathrm{C}$ per $\mathrm{cm}$, and thermal probes were embedded in the block every $1.2 \mathrm{~cm}$. There were 20 observation fields for recording the distribution of whiteflies. A $0.1 \mathrm{~cm}$ high glass cover confined the whiteflies to the thermal gradients and ensured that adults could migrate freely. Experiments were carried out in dark conditions to prevent the effects of light on temperature preference [53]. Previous studies showed that the state of whiteflies was stable when they moved for $2 \mathrm{~h}$ in the darkness. Therefore, in this study, whitefly adults were placed between the aluminum block and the glass cover; they were then allowed to migrate into darkness for $2 \mathrm{~h}$. Finally, the number of whiteflies in each region was counted. The experiments were performed in a room with the temperature maintained at $26{ }^{\circ} \mathrm{C}$. There were four repetitions for each treatment, containing 200 adults in each repetition and the ratio of females:males was 1:1.

\subsection{Statistical Analysis}

The mRNA expression levels were calculated with the $2^{-\Delta \Delta C T}$ method: $\left[\Delta \Delta C T=\left(\mathrm{Ct}_{\text {target }}-\right.\right.$ $\left.\left.C t_{\text {reference }}\right)_{\text {treatment }}-\left(\mathrm{Ct}_{\text {target }}-\mathrm{Ct}_{\text {reference }}\right)_{\text {control }}\right][54,55]$. Statistical analyses were carried out using the SAS 9.4 software package (SAS Institute, Inc., Cary, North Carolina). We used one-way analysis of variance (ANOVA), followed by Duncan's multiple range tests to compare the differences between control and treatment groups. Data are presented as mean \pm standard error (mean $\pm \mathrm{SEM}$ ). Differences were considered significant when $p<0.05$.

\section{Results}

\subsection{Characterization of BtISWI}

The complete cDNA of BtISWI consists of 3712 nucleotides and contains a $232 \mathrm{bp} 5^{\prime}$-UTR (residues 1-232), a 411-bp 3'-UTR (residues 3302-3712), and a 3069 bp ORF (residues 233-3301) (Figure 1). This ORF encodes a predicted protein of 1022 amino acid residues, with a calculated molecular mass of $118.86 \mathrm{kDa}$ and an isoelectric point $(\mathrm{pI})$ of 8.36. Conserved domains analysis of the deduced protein sequence showed that BtISWI contains the N-terminal ATPase domain (DEXDc positions 137-324 and HELICc positions 474-558), and the C-terminal HAND (positions 704-804), SANT (SWI3, ADA2, N-CoR, TFIIIB domains)(positions 805-855), and SLIDE (SANT-like ISWI domain) (positions 890-984) domains (Figure 2A). In addition, we used homology modeling in the Swiss-model to further refine and confirm the above predictions. BtISWI had similar functional domains compared to Drosophila melanogaster (the similarity was 85.39\%, QMEAN (Qualitative Model Energy Analysis) was 0.14 and GMQE (Global Model Quality Estimation) was 0.74) (Figure 2B); the HAND domain has four helices (H1, H2, H3, and H4), the SANT domain contains three helices (SA1, SA2, and SA3), and the SLIDE domain also consists of three helices (SL1, SL2, and SL3). The SANT and SLIDE domains are connected by a continuous $\alpha$-helix (SP). Moreover, multiple sequence alignment (Figure 3) and phylogenetic analyses (Figure 4) indicated that insect ISWI genes were highly conserved throughout evolution, and the ISWI proteins of insects in the same order clustered on the same branch of the phylogenetic tree. 
GGTTTTTCCTTCCGCATGAGAGACCTTTCTTCTCTTGTGTTTACAAGTCACAGTGATTTTATTGTGAATTTCTCAACACTTACGTTTTTTCTGAAGTGC GTTACCTTATAATTTTATATCAAAGACTAATTTTTAATTACCTGACGAAACATCATCCATTTTTATTGTAGTGTTGTAATCCATCGGAACTTATCCGGT ATTTTTGAGTGCGTGCAAGGTATCTTTTGTCAAAATGGTTAAAACGGGGTCTGAAAACCGGTCAGACGACGGTTCCGATGGTGAAGAATTGTCGAACGA M $\quad$ V ATCATCCTCTATGGAAGCTCCGCCCGCTCCGAAAAGTCTTAAAGCAGAATTCGATAAACCTGGAGTTGACCAGAGTAAGCGCTTTGAATTCTTACTAAA $\begin{array}{llllllllllllllllllllllllllllllllll}S & S & S & M & E & A & P & P & A & P & K & S & L & K & A & E & F & D & K & P & G & V & D & Q & S & K & R & F & E & F & L & L & K\end{array}$ ACAGACCGAAATTTTCTCTCACTTCATGACGAACAGCAACAAGGATAAAACTTCCCCAACAACCACTGGAAAACCTAAAGGTAGGCCTCGGAAAGAACA $\begin{array}{llllllllllllllllllllllllllllllllll}Q & T & E & I & F & S & H & F & M & T & N & S & N & K & D & K & T & S & P & T & T & T & G & K & P & K & G & R & P & R & K & E & Q\end{array}$ ACCCAAATCCTCCGATTCACCCTCTAAAGATTCTGCTGATCATCGTCACCGGAAAACAGAGCAAGAGGAAGATGAAGAACTACTGGCTGAGAGTAACGC $\begin{array}{lllllllllllllllllllllllllllllllll}P & K & S & S & D & S & P & S & K & D & S & A & D & H & R & H & R & K & T & E & Q & E & E & D & E & E & L & L & A & E & S & N & A\end{array}$ AGCCACAAAGACCATAACCATGTTTGACTCCTCACCATTCTACATTAAAAATGGTGAATTACGAGATTACCAAGTTCGTGGTCTAAACTGGATGATTTC $\begin{array}{lllllllllllllllllllllllllllllllll}\text { A } & T & K & T & I & T & M & F & D & S & S & P & F & Y & I & K & N & G & E & L & R & D & Y & Q & V & R & G & L & N & W & M & I & S\end{array}$ TCTCTTTGAAAACGGCATTAACGGTATTCTTGCCGATGAGATGGGTCTAGGTAAAACCCTTCAAACCATCTCGCTACTTGGTTACATGAAGAACTTCCG L F CAACATCTCTGGCCCTCATATGGTCATTGTCCCTAAGTCAACCTTGATGAACTGGATGAATGAATTCAAAAAGTGGTGTCCCTCGCTGAAAGCAGTTTC $\begin{array}{llllllllllllllllllllllllllllllllll}N & I & S & G & P & H & M & V & I & V & P & K & S & T & L & M & N & W & M & N & E & F & K & K & W & C & P & S & L & K & A & V & C\end{array}$ TTTAATTGGAGACCAAGAAGCTCGTAATAATTTCATCAGAGACGTTTTAATGCCTGGAGACTGGGACGTTTGTGTAACTTCTTATGAAATGATCATTCG $\begin{array}{llllllllllllllllllllllllllllllllll}L & I & G & D & Q & E & A & R & N & N & F & I & R & D & V & L & M & P & G & D & W & D & V & C & V & T & S & Y & E & M & I & I & R\end{array}$ AGAGAAAAGCACCTTGAAGAAATTTAATTGGCGTTACATGGTCATTGACGAAGCTCACCGTATTAAAAACGAGAAATCCAAGTTATCAGAAATTGTTCG $\begin{array}{llllllllllllllllllllllllllllllllll} & \text { E } & K & S & T & L & K & K & F & N & W & R & Y & M & V & I & D & E & A & H & R & I & K & N & E & K & S & K & L & S & E & I & V & R\end{array}$ AGAATTCAAGACAACCAACAGATTGCTGCTAACTGGAACTCCATTACAAAACAACCTTCATGAGTTATGGTCTCTGTTGAATTTCTTGCTACCTGATGT $\begin{array}{llllllllllllllllllllllllllllllllll}\text { E } & F & K & T & T & N & R & L & L & L & T & G & T & P & L & Q & N & N & L & H & E & L & W & S & L & L & N & F & L & L & P & D & V\end{array}$ CTTTAATTCATCAGATGATTTTGATGCATGGTTCAATACGAATACTTGTCTTGGTGACAATGCACTTGTTGAAAGATTGCATGCAGTTTTAAGACCTTT

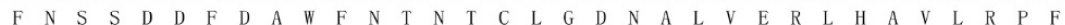
CTTGTTGCGTCGTCTCAAGTCTGAAGTGGAAAAGCGATTGAAACCCAAAAAAGAATTAAAGGTGTATGTTGGCTTAAGTAAAATGCAAAGAGAGTGGTA $\begin{array}{lllllllllllllllllllllllllllllllll}L & L & R & R & L & K & S & E & V & E & K & R & L & K & P & K & K & E & L & K & V & Y & V & G & L & S & K & M & Q & R & E & W & Y\end{array}$ TACTAAAGTCCTGATGAAAGATATTGACATTGTGAATGGTGCTGGAAAAATTGAGAAAATGCGGCTTCAAAACATCCTGATGCAACTGCGAAAGTGCTC $\begin{array}{lllllllllllllllllllllllllllllllll}T & K & V & \text { L } & M & K & D & I & D & I & V & N & G & A & G & K & I & E & K & M & R & L & Q & N & I & L & M & Q & L & R & K & C & C\end{array}$ TAACCACCCGTATCTTTTTGATGGCGCTGAACCTGGTCCACCATATACAACAGATGAGCACTTGGTATTTAACTGTGGCAAAATGGTCATTCTTGATAA

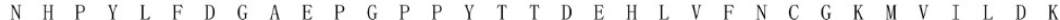
GCTGCTGCCGAAATTACAAGAACAAGACTCAAGGGTGCTAATTTTTAGTCAAATGACGCGTATGATTGACATCCTTGAAGATTTCTGCCACTGGCGTGC $\begin{array}{llllllllllllllllllllllllllllllllll}\mathrm{L} & \mathrm{L} & \mathrm{P} & \mathrm{K} & \mathrm{L} & \mathrm{Q} & \mathrm{E} & \mathrm{Q} & \mathrm{D} & \mathrm{S} & \mathrm{R} & \mathrm{V} & \mathrm{L} & \mathrm{I} & \mathrm{F} & \mathrm{S} & \mathrm{Q} & \mathrm{M} & \mathrm{T} & \mathrm{R} & \mathrm{M} & \mathrm{I} & \mathrm{D} & \mathrm{I} & \mathrm{L} & \mathrm{E} & \mathrm{D} & \mathrm{F} & \mathrm{C} & \mathrm{H} & \mathrm{W} & \mathrm{R} & \mathrm{G}\end{array}$ ATACAAGTATTGCAGGTTAGATGGTCAAACTCCCCATGAAGATCGACAGCGGCAGATCAATGAATTTAATGCCCCAAACAGCGACAAATTCATTTTCAT

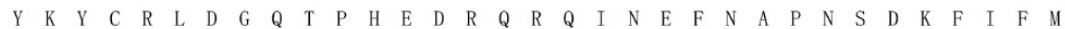
GTTGTCAACTCGCGCTGGTGGTCTTGGTATCAACTTGGCAACTGCAGATGTAGTTATCATTTATGATTCTGACTGGAATCCTCAAATGGACTTGCAGGC $\begin{array}{llllllllllllllllllllllllllllllllll}L & S & T & R & A & G & G & L & G & I & N & L & A & T & A & D & V & V & I & I & Y & D & S & D & W & N & P & Q & \text { M } & \text { D } & \text { L } & Q & A\end{array}$ CATGGACCGAGCTCATCGTATAGGTCAGAAAAAACAAGTGCGAGTTTTCCGACTAATCACCGAAAATACCGTTGAGGAAAAAATTGTTGAAAGAGCAGA $\begin{array}{llllllllllllllllllllllllllllllllll}M & D & R & A & H & R & I & G & Q & K & K & Q & V & R & V & F & R & L & I & T & E & N & T & V & E & E & K & I & V & E & R & A & E\end{array}$ AGTGAAATTACGTCTGGACAAGCTGGTCATTCAACAAGGTCGCTTAGTCGACAACAAGGCTGCTCTCCAAAAAGACGAAATGCTTAACATGATTCGGCA

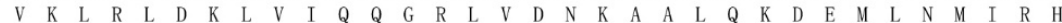
TGGTGCCAATCATGTCTTTGCTTCAAAAGACTCAGAAATTACAGATGAAGATATTGATACAATTCTTGAGAAAGGTGAGGCTAAGACTGAAGAGATGAA $\begin{array}{llllllllllllllllllllllllllllllllll}G & A & N & H & V & F & A & S & K & D & S & E & I & T & D & E & D & I & D & T & I & L & E & K & G & E & A & K & T & E & E & M & K\end{array}$ GCAAAAGCTAGAAACGCTCGGGGAATCCTCTCTTCGAAATTTCACTCTCGATGCTCCCACTGAATCTGTTTATCAGTTTGAAGGGGAAGACTACCGTGA

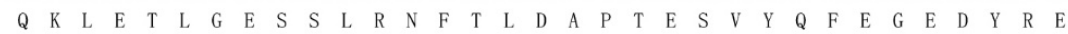
AAAGCAAAAACTCACCGGGATTGGAAATTGGATTGAGCCTCCTAAGAGAGAGAGGAAAGCAAACTATGCTGTCGATGCATATTTCCGTGAAGCGCTCCG $\begin{array}{llllllllllllllllllllllllllllllllll}K & Q & K & L & T & G & I & G & N & W & I & E & P & P & K & R & E & R & K & A & N & Y & A & V & D & A & Y & F & R & E & A & L & R\end{array}$ AGTTTCAGAACCGAAAGCACCAAAAGCTCCAAGACCTCCAAAACAACCAATTGTCCAAGATTTCCAGTTCTTTCCAATGCGTCTATTTGAGCTGTTAGA $\begin{array}{llllllllllllllllllllllllllllllllll}V & S & E & P & K & A & P & K & A & P & R & P & P & K & Q & P & I & V & Q & D & F & Q & F & F & P & M & R & L & F & E & L & L & D\end{array}$ TCAAGAAATCTACTATTTCCGCAAGTCAGTGGGCTACCGGGTACCCAAGAACCCTGAGTTGGGTGTAGATGCAAACAAAATACAGAAAGAAGAGCAGAA $\begin{array}{llllllllllllllllllllllllllllllllll}Q & E & I & Y & Y & F & R & K & S & V & G & Y & R & V & P & K & N & P & E & L & G & V & D & A & N & K & I & Q & K & E & E & Q & K\end{array}$ GAAGATCGACGAGGCACAACCACTGACTGAAGAAGAACTATTGGAAAAAGAAGATCTTCTGACGCAAGGATTTACCAACTGGACGAAGCGTGATTTCAA

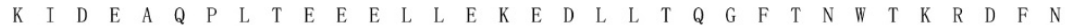
CCAATTCATAAAAGCTAATGAAAAATTTGGTAGAGACGATATTCACAACATTTGCAAGGAAGTCGAAGGCAAAACCCCCGAAGAAGTTATAGAGTATAG $\begin{array}{llllllllllllllllllllllllllllllllll}Q & F & I & K & A & N & E & K & F & G & R & D & D & I & H & N & I & C & K & E & V & E & G & K & T & P & E & E & V & I & E & Y & S\end{array}$ CAGTGTATTTTGGGAACGCTGTCAGGAATTACAAGATATTGAACGAATAATGGCTCAAATAGAACGTGGTGAAGCAAAAATCCAACGCCGTGCCAGTAT $\begin{array}{llllllllllllllllllllllllllllllllll}S & V & F & W & E & R & C & Q & E & L & Q & D & I & E & R & I & M & A & Q & I & E & R & G & E & A & K & I & Q & R & R & A & S & I\end{array}$ AAAGCGAGCCTTAGATGCTAAAATGGAGAGGTATCAAGCGCCATTCCACCAGCTGAGAATATCCTACGGCACAAACAAAGGCAAAAACTACACCGAAGA $\begin{array}{llllllllllllllllllllllllllllllllll}K & R & A & L & D & A & K & M & E & R & Y & Q & A & P & F & H & Q & L & R & I & S & Y & G & T & N & K & G & K & N & Y & T & E & E\end{array}$ AGAAGATCGGTTTTTGGTTTGTATGTTGCATCGACTTGGATTCGACAAGGAGAATGTGTATGAAGAACTCCGATCTGCAACAAGGTTTGCCCCTCAGTT

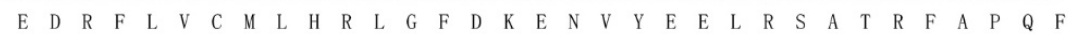
CCGCTTTGACTGGTTCATCAAGAGCAGAACTGCGATGGAATTGCAGCGACGATGTAACACATTAATCACACTCATTGAGCGAGAAAATCAAGAACTAGA $\begin{array}{lllllllllllllllllllllllllllllllll}R & F & D & W & F & I & K & S & R & T & A & M & E & L & Q & R & R & C & N & T & L & I & T & L & I & E & R & E & N & Q & E & L & E\end{array}$ GGAGAAAGAGAAAGCAGCTGACAAAACAAAGAACAAGCGAGGGCCTCGTGCTGGCCAAGGCAAACGGAAAAGCGAAGCTAACGCTGTGGCCGATTCGAA $\begin{array}{llllllllllllllllllllllllllllllllll}E & K & E & K & A & A & D & K & T & K & N & K & R & G & P & R & A & G & Q & G & K & R & K & S & E & A & N & A & V & A & D & S & K\end{array}$ ACCAACCTCAGCTAAAAAGAAGAAAAAGAACTAAAAATCCTCGAGTCAGGTGTTTCTTCTCAATTTCTCGGTGTACAGTCCTGAACTTGAAAATTTTGA $\begin{array}{lllllllllllllll}P & T & S & A & K & K & K & K & K & N\end{array}$

GCTGTTTTAATTTTGTCCAGACAGAAATTTCAGTTTGTATAAAGCACACTATTTGCTTTAAATAAGAATCCTCCTCCTTTCATCTTAATTTCTGATAAA CTTATGAATTTGTAAATAGTCATTTGATATCTCTAAAGAAACAACTAAGTAAAGTGAGGATAATATTCTCAGCTGCATATTTCATGTGAGAAAAAGGGC ATAACTGAGAATATATCTGATAGACTCATCTTGGCATCAATGGTATGCCCTCCTTACATTGATGAATCAGTTTCTATCAAGGTGGCCAATCAAAATGAT TCGGTCTCTTTTTCCTGTACCTGTGATTACTTAGAATGTAGGTATTTAA

Figure 1. This The full-length cDNA sequence of Bemisia tabaci MEAM1 BtISWI and its deduced amino acid sequence. The full-length cDNA of MEAM1 BtISWI is $3712 \mathrm{bp}$, and the ORF (233-3301 bp) encodes a polypeptide of 1022 amino acids. 
A

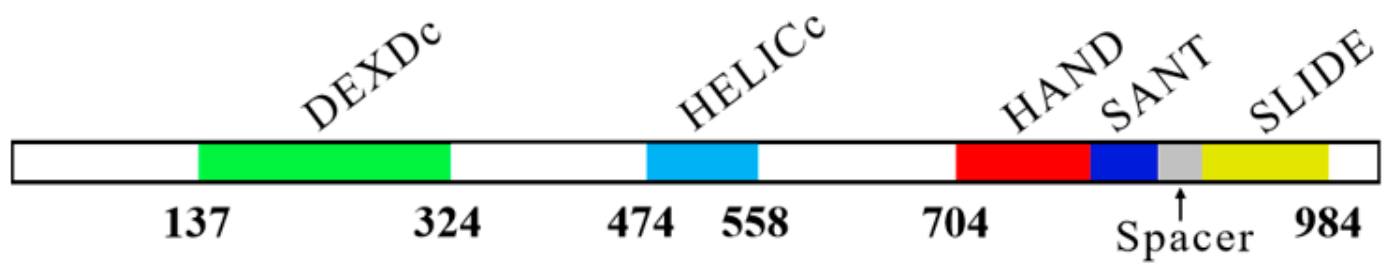

B
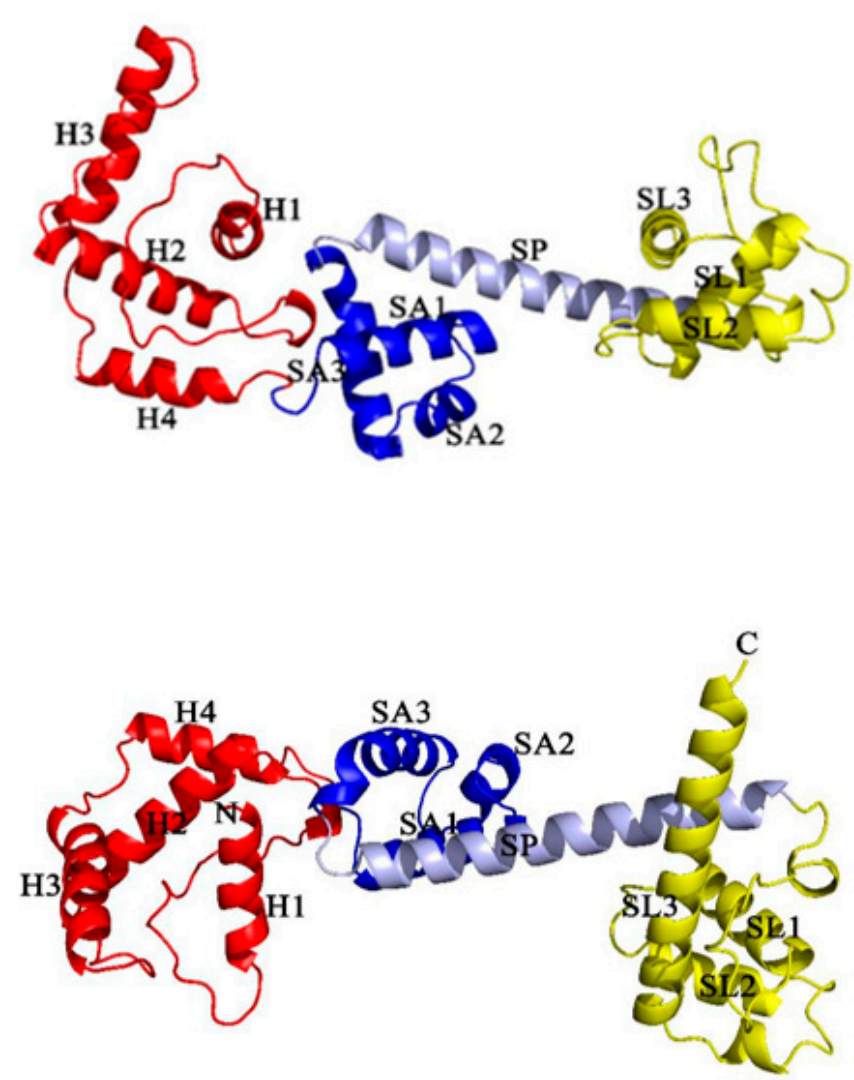

Figure 2. Functional domains in Bemisia tabaci MEAM1 BtISWI protein (A) and two orthogonal views of the predicted BtISWI C-terminal structure (B). The DEXDc domain is depicted in green, HELICc domain in baby blue, HAND domain in red, SANT (SWI3, ADA2, N-CoR, TFIIIB) domain in blue, SLIDE (SANT-like ISWI) domain in yellow, and the spacer helix connecting the SANT and SLIDE domains in gray. 


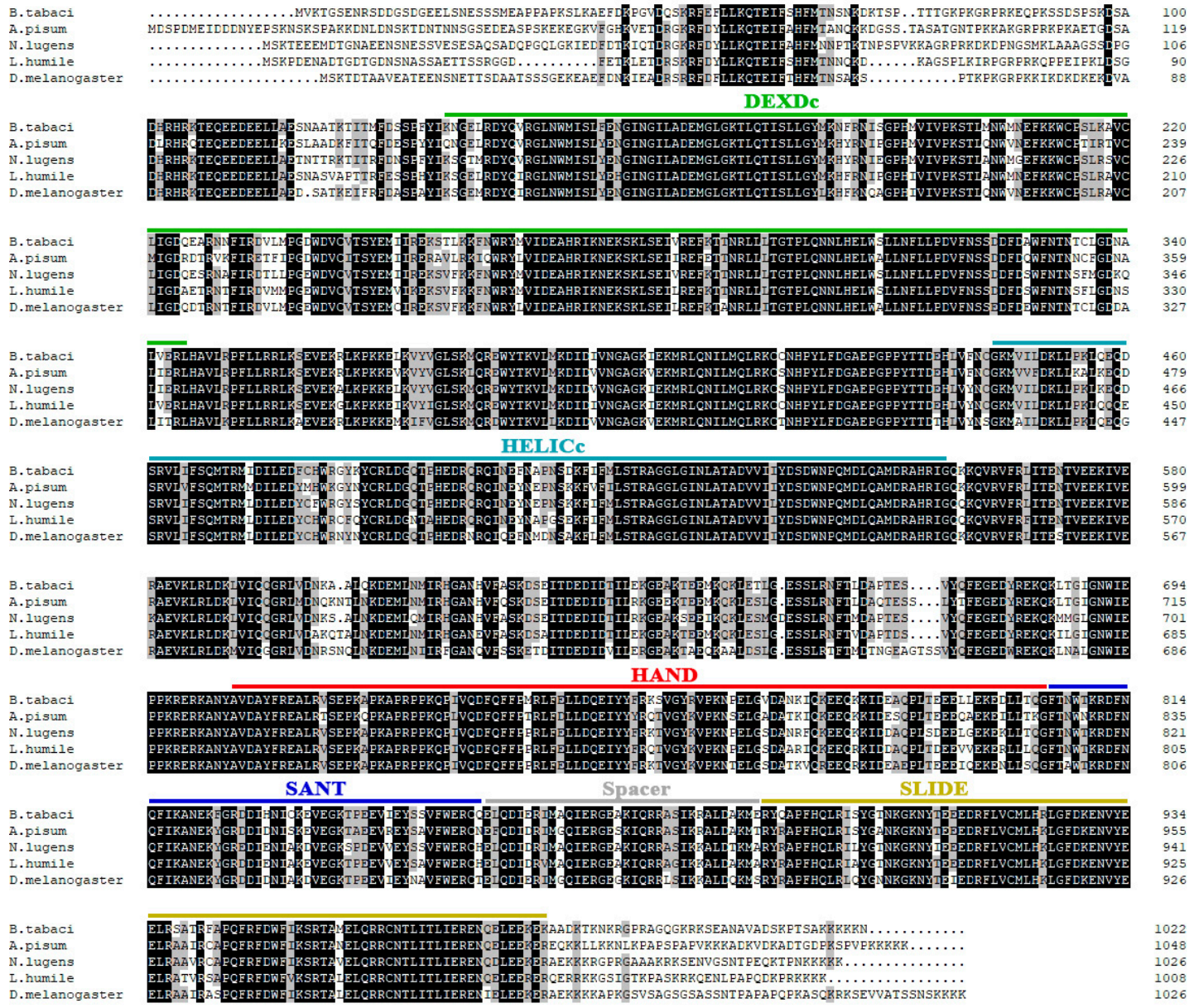

Figure 3. Multiple alignments of the imitation switch (ISWI) protein sequences from Bemisia tabaci MEAM1 and other insects. The conserved domains are highlighted in the same colors as in Figure 2. Multiple sequence alignment revealed that the deduced amino acid sequence of BtISWI is highly conserved when compared to previously identified ISWI amino acid sequences. B. tabaci: Bemisia tabaci; A. pisum: Acyrthosiphon pisum (XP_001945595.1); N. lugens: Nilaparvata lugens (XP_022189967.1); L. humile: Linepithema humile (XP_012220642.1); and D. melanogaster: Drosophila melanogaster (NP_523719.1). 


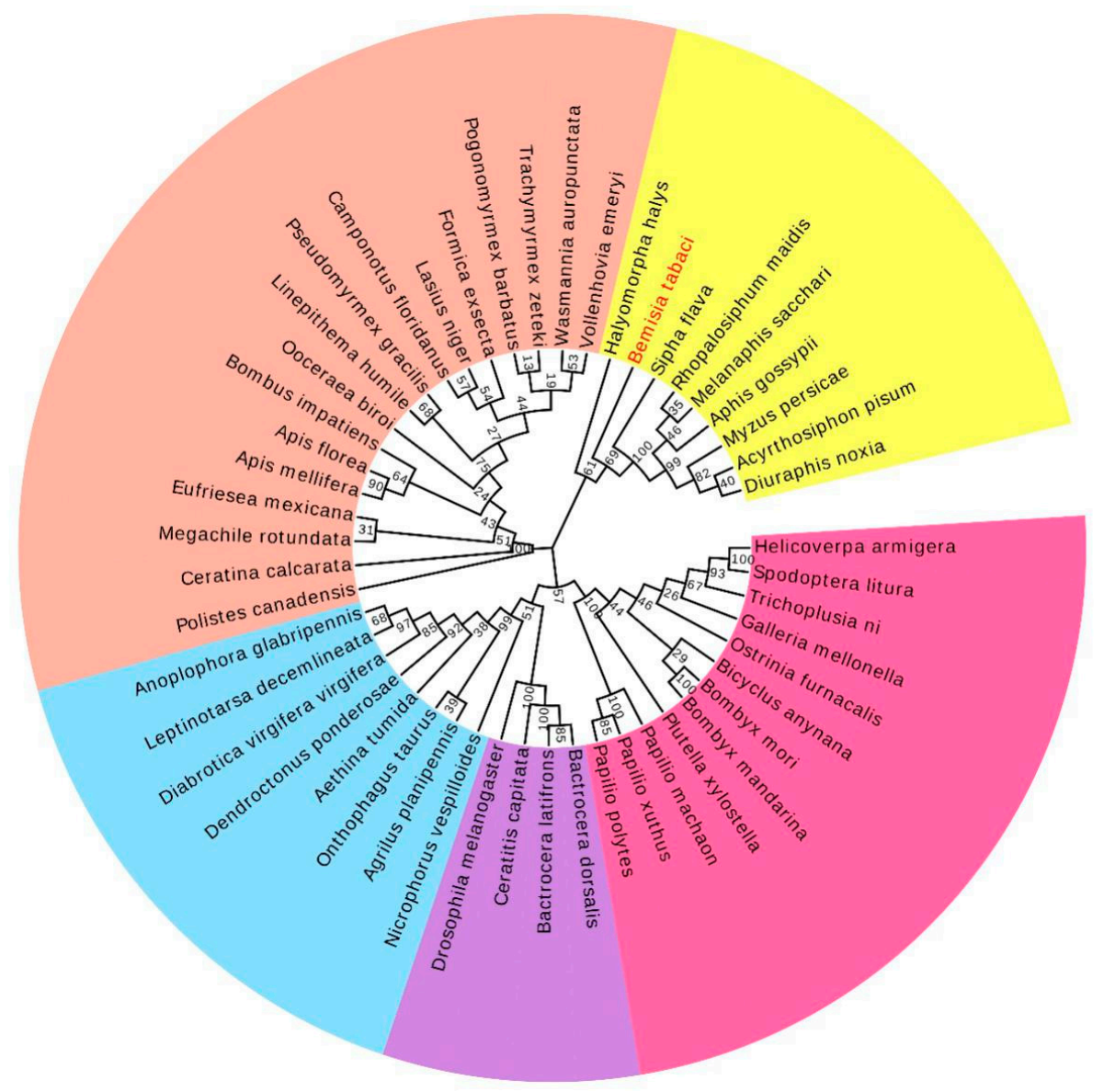

Figure 4. A phylogenetic tree based on the known amino acid sequences of ISWI genes. The phylogenetic tree was constructed using the maximum likelihood method with 1000 bootstrap replications in MEGA 7.0 software. Numbers at the nodes of the branches represent the level of bootstrap support for each branch. Insects in the same order clustered on the same branch. Lepidoptera is depicted in pink, Diptera in purple, Coleoptera in baby blue, Hymenoptera in dusty pink, and Hemiptera in yellow. Table S1 shows the ISWI protein sequences used for phylogenetic analysis.

\subsection{Expression Profiles of BtISWI in Response to Thermal Stress}

qRT-PCR was carried out to investigate whether thermal stress affects the expression profiles of BtISWI. The results showed that, compared to the whiteflies maintained at $26{ }^{\circ} \mathrm{C}$ (the control temperature), mRNA expression levels of MEAM1 BtISWI were significantly up-regulated after exposure to heat shock or cold shock conditions (except for those exposed to $12{ }^{\circ} \mathrm{C}$ for $1 \mathrm{~h}$ ) (Figure 5). These data suggested that the expression of BtISWI was affected by thermal stress. 


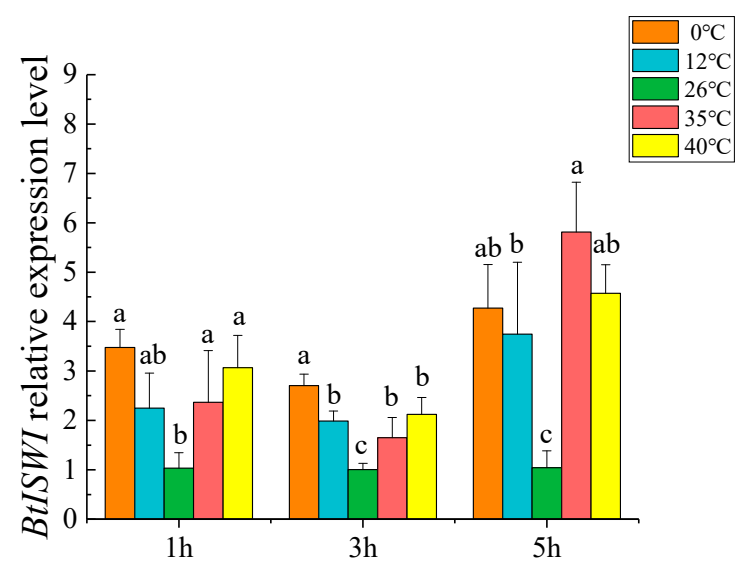

Figure 5. Relative expression levels of MEAM1 BtISWI after exposure to different temperatures. BtISWI mRNA expression was significantly up-regulated (except for exposure to $12{ }^{\circ} \mathrm{C}$ for $1 \mathrm{~h}$ ) after exposure to heat shock and cold shock compared to the controls $\left(26^{\circ} \mathrm{C}\right.$, and the BtISWI mRNA expression at this temperature was stable all the time). The relative expression levels are expressed as the mean $\pm \mathrm{SEM}$. Bars with different lowercase letters are significantly different at $p<0.05$.

\subsection{BtISWI mRNA Expression Level after Feeding dsRNA}

In order to further explore the function of BtISWI, we fed MEAM1 adults with dsRNA to silence BtISWI gene expression. Compared with controls-whiteflies that were untreated or those fed with dsRNA targeting enhanced GFP (dseGFP) or 10\% sucrose-the BtISWI mRNA expression level was decreased by $43.10 \%$ after feeding with $d s I S W I$ for $3 \mathrm{~h}$ (Figure 6).

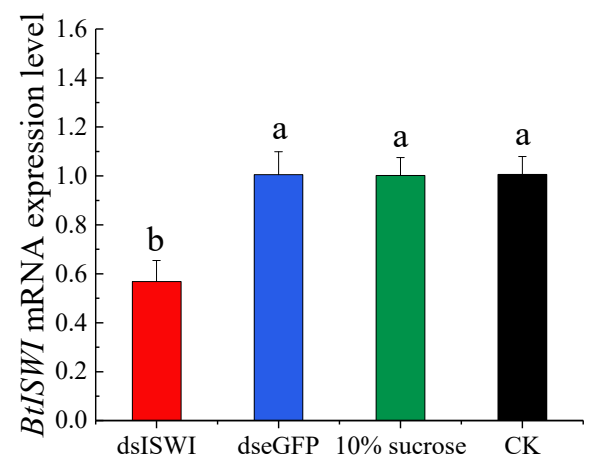

Figure 6. Effect of double-stranded RNA (dsRNA) treatment on Bemisia tabaci MEAM1 BtISWI mRNA expression level. BtISWI mRNA expression in whiteflies fed BtISWI dsRNA (dsISWI) for $3 \mathrm{~h}$ was significantly decreased compared to the controls: whiteflies untreated or fed eGFP dsRNA (dseGFP) or $10 \%$ sucrose. The expression levels are expressed as the mean \pm SEM. Bars with different lowercase letters are significantly different at $p<0.05$.

\subsection{The Role of BtISWI in Temperature Stress}

The thermal tolerance of MEAM1 adults fed with dsRNA targeting BtISWI was significantly reduced, manifested by a shorter heat shock tolerance time (Figure 7A) and a longer chill coma recovery time (Figure 7B). The mean tolerancetimes after $45 \pm 0.2^{\circ} \mathrm{C}$ heat shock for whiteflies that were untreated or fed with $10 \%$ sugar, dseGFP, or dsBtISWI were $26.51 \pm 1.06 \mathrm{~min}, 26.23 \pm 0.38 \mathrm{~min}$, $26.86 \pm 0.84 \mathrm{~min}$, and $16.12 \pm 1.32 \mathrm{~min}$, respectively. The mean chill coma recovery times (Figure 7B) after 10 min exposure to $-5 \pm 0.2{ }^{\circ} \mathrm{C}$ for MEAM1 individuals that were untreated, or those fed with $10 \%$ sugar, dseGFP, or dsBtISWI were $6.11 \pm 0.32 \mathrm{~min}, 6.28 \pm 0.19 \mathrm{~min}, 6.25 \pm 0.37 \mathrm{~min}$, and $8.99 \pm$ $0.13 \mathrm{~min}$, respectively. These results suggested that BtISWI might be essential in the thermal resistance of MEAM1 adults. 


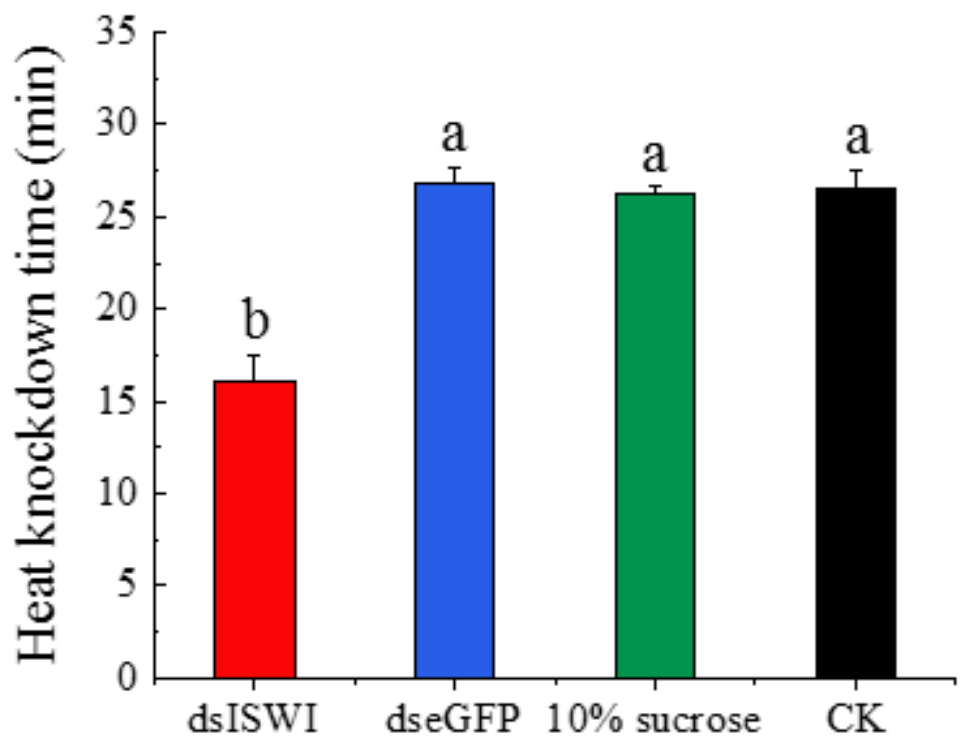

(A)

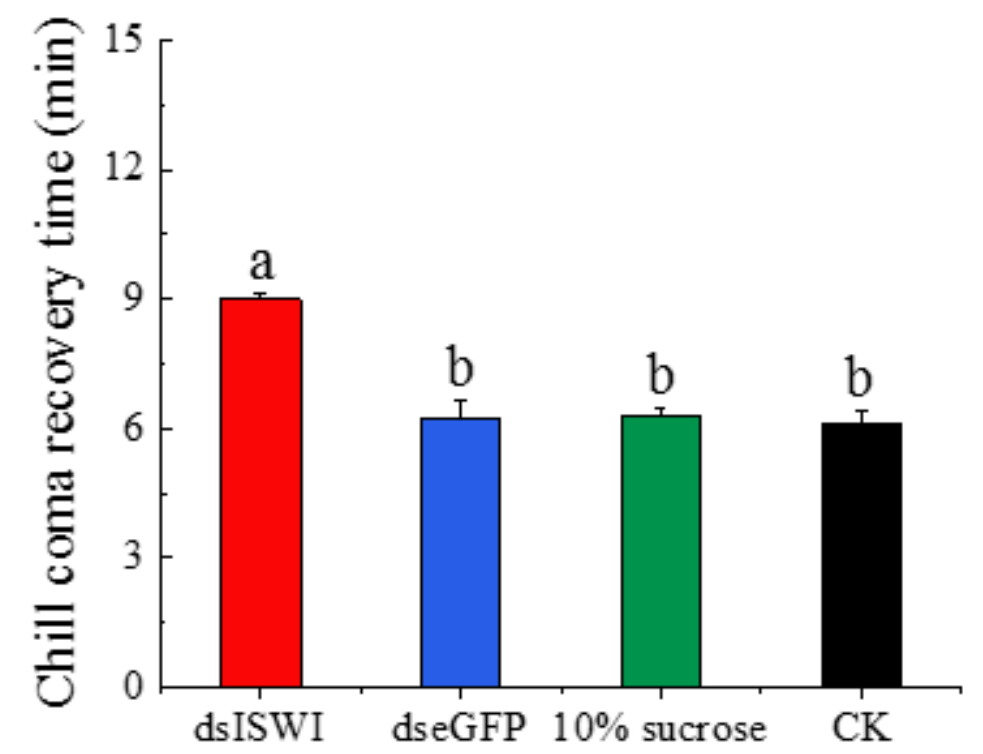

(B)

Figure 7. Mean heat tolerance time and chill coma recovery time after double-stranded RNA (dsRNA) feeding in MEAM1 adults. Compared with the control groups (whiteflies untreated or fed dseGFP or $10 \%$ sucrose), the mean heat tolerance time for whiteflies fed dsISWI was significantly decreased (A), whereas the mean chill coma recovery time was significantly increased (B). The data are presented as the mean $\pm S E M ; N=200$. Bars with different lowercase letters are significantly different at $p<0.05$.

\subsection{The Choice of Preferred Temperature}

In order to examine whether the temperature preference of MEAM1 adults changed after dsRNA feeding, a linear thermal gradient ranging from 12 to $30^{\circ} \mathrm{C}$ was tested. The results showed that the preferred temperature for untreated whiteflies was $13.8^{\circ} \mathrm{C}$ (Figure 8), with the percentage of whiteflies $(21.98 \pm 4.49 \%)$ in this area significantly exceeding those of the other temperature regions. The preferred 
temperature for whiteflies fed $10 \%$ sugar or fed dseGFP was consistent with the untreated whiteflies (the percentages of preferred temperature region were $19.60 \pm 2.02 \%$ and $19.76 \pm 3.13 \%$, respectively). When the temperature preference was tested in individuals subjected to dsISWI feeding, they exhibited temperature preferences of $15.7^{\circ} \mathrm{C}$ and $17.3^{\circ} \mathrm{C}$, with percentages of whiteflies in these two areas of $21.50 \pm 3.49 \%$ and $20.36 \pm 3.55 \%$, respectively. ANOVA analyses showed that the distribution of whiteflies in these two regions significantly exceeded others, but there was no significant difference between them (Figure 8). These results implied that the temperature preference of MEAM1 changed after dsISWI feeding.

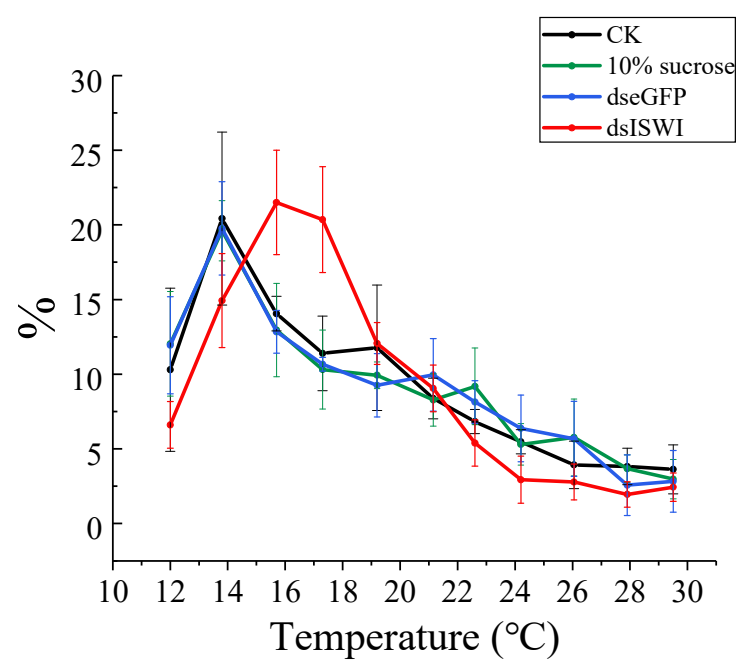

Figure 8. Temperature preference response of MEAM1 adults. The number of whiteflies in each biological replicate was 200, and there were four repetitions for each treatment. Compared to the control treatments (whiteflies untreated, or fed dseGFP or 10\% sucrose), whiteflies fed dsISWI showed a higher preferred temperature and a wider distribution range of favorable temperatures. The data are presented as the mean \pm SEM.

\section{Discussion}

In this study, the full cDNA sequence of the ISWI gene in invasive MEAM1 was reported. We found that BtISWI had the same structural organization with ISWI identified previously in other species: A highly conserved ATPase domain in the N-terminal half of the ISWI protein and a representative HAND-SANT-SLIDE domain in the C-terminal half of the protein (Figure 2A) [56]. Research on ISWI structural domains has shown that efficient remodeling depends on the presence of the C-terminal HAND-SANT-SLIDE domain [57,58]. Remarkably, the C-terminal end of MEAM1 shared 74.32\% sequence similarity with other insects, indicating that the function of ISWI is relatively conserved across species. In addition, the phylogenetic tree showed that ISWI proteins of insects in the same order clustered on the same branch (Figure 4), consistent with traditional taxonomy.

The small invasive insect MEAM1, which is thought to originate in the Middle East-Asia Minor region, has successfully colonized and spread to at least 54 countries $[29,59]$, mainly due to its rapid adaption to various temperature conditions $[35,60,61]$. In the present study, the mRNA expression level of MEAM1 BtISWI was significantly upregulated after adults were exposed to high or low temperatures, up to the highest level after exposure to $35^{\circ} \mathrm{C}$ for $5 \mathrm{~h}$ (Figure 5). Interestingly, for the same high temperature stress conditions, previous research found that the onset temperatures for the synthesis of $h s p 20, h s p 70$, and $h s p 90$ were $35^{\circ} \mathrm{C}, 39^{\circ} \mathrm{C}$, and $35^{\circ} \mathrm{C}$, respectively [62]. These data showed that the onset temperature for $h s p 20$ and $h s p 90$ expression was consistent with the temperature for inducing BtISWI expression up to the highest level, and the onset temperature for $h s p 70$ expression was generally $4{ }^{\circ} \mathrm{C}$ higher. Furthermore, studies in Drosophila showed that NURF, a chromatin-remodeling complex that contains ISWI as its ATPase subunit, cooperated with the GAGA factor to mobilize 
nucleosomes on the promoter of the heat-shock genes, creating a nucleosome-free domain over the promoter, thus exposing suitable sites for the heat-shock TF [21,63]. Collectively, these results indicated that BtISWI might improve the ability of MEAM1 individuals to adapt rapidly to various temperature conditions by inducing the expression of stress-related genes, such as heat-shock protein genes.

ISWI-containing chromatin remodeling complexes function directly in the thermal adaption of organisms. For example, Erkina et al. [23] demonstrated that combinatorial inactivation of ISWI and SNF2 had a strong synergistic effect by diminishing histone loss during heat induction and eliminating Pol II recruitment. Importantly, this inactivation also eliminated preloading of HSF promoters before heat shock, which is the primary regulator of most HSP genes [23,64]. In addition, the generation of an accessible heat shock promoter in chromatin in Drosophila required the concerted action of the GAGA TF and the ISWI-containing complex (dNURF) [21,63]. In this study, the functions of the MEAM1 BtISWI in thermal tolerance were identified using RNAi. Results showed that the mean heat tolerance time of MEAM1 adults fed BtISWI dsRNA was significantly decreased and the mean chill coma recovery time was significantly increased (Figure 7). The mechanisms of the response to high-temperature tolerance and low-temperature chill coma recovery are, in some respects, probably closely related to the thermal stress response [65]. Hence, it is reasonable to conclude that BtISWI has important effects on the thermal tolerance of MEAM1. However, only the common subunit of ISWI was researched in the present study, so further study is needed to determine the specific ISWI complexes essential for the thermal tolerance of whiteflies.

Due to a temperature preference rhythm, (for example, the preferred temperature in Drosophila rises during the day and falls during the night) [66,67], our experiments were conducted during the same periods of one day. Compared with D. melanogaster or Apolygus lucorum, whose preferred temperature was consistent with their optimum temperature range [68,69], whitefly adults exhibited a lower temperature preference than their optimum temperature. Similarly, Kinzner et al. [70] also found that adults of the tropical $D$. birchii had a low temperature preference of $16.7^{\circ} \mathrm{C}$. The preferred temperature is theoretically expected to be in a similar range than the optimum temperature of maximum physiological performance, but empirically, the preferred temperature can be lower than the optimum temperature [70,71]. Furthermore, in the present study, after feeding BtISWI dsRNA, the preferred temperature of the MEAM1 adults was about $1.9-3.5^{\circ} \mathrm{C}$ higher than the control groups (Figure 8). In addition, whiteflies fed BtISWI dsRNA showed a wider range of favorable temperatures than controls. Organisms that are good at thermoregulation may distribute across a relatively narrow range of favorable temperatures [72-74]. Therefore, the results of this study indicated that the ISWI gene might be involved in the temperature regulation of the invasive insect $B$. tabaci and affect its temperature preference behavior.

\section{Conclusions}

Previous studies on ISWI have focused on model organisms, such as Drosophila, yeast, nematodes, mouse, and Arabidopsis thaliana. This study was the first to reveal the characteristics of BtISWI in invasive B. tabaci MEAM1 and to identify the functions of BtISWI using RNAi. Moreover, the temperature preference behavior of whiteflies was first measured in the present study. The results of this study demonstrated that BtISWI played an essential role in thermal tolerance and may participate in the temperature regulation of MEAM1. Our findings highlighted the importance of epigenetic gene regulation in the thermal response and thermal adaptation of invasive insects. Furthermore, this study provides a new potential target to establish sustainable control strategies for insect pests.

Supplementary Materials: The following are available online at http://www.mdpi.com/2075-4450/11/2/113/s1, Table S1: Details of ISWI protein sequences used for phylogenetic analysis.

Author Contributions: Z.-C.L., W.-X.L. and F.-H.W. conceived and designed the research. S.-X.J. and X.-D.W. contributed materials and performed the experiments. S.-X.J., X.-N.S. and L.L. analyzed the data. S.-X.J. wrote the manuscript. All authors have read and agreed to the published version of the manuscript. 
Funding: This research was funded by the National Natural Science Foundation of China (31672088 and 31601695) and the National Key Research and Development Program (2017YFC1200600).

Acknowledgments: In this section you can acknowledge any support given which is not covered by the author contribution or funding sections. This may include administrative and technical support, or donations in kind (e.g., materials used for experiments).

Conflicts of Interest: The authors declare no conflict of interest.

\section{References}

1. An, P.N.T.; Shimaji, K.; Tanaka, R.; Yoshida, H.; Kimura, H.; Fukusaki, E.; Yamaguchi, M. Epigenetic regulation of starvation-induced autophagy in Drosophila by histone methyltransferase G9a. Sci. Rep. 2017, 7, 7343. [CrossRef]

2. Stankiewicz, A.M.; Swiergiel, A.H.; Lisowski, P. Epigenetics of stress adaptations in the brain. Brain Res. Bull. 2013, 98, 76-92. [CrossRef] [PubMed]

3. Skinner, M.K.; Manikkam, M.; Guerrero-Bosagna, C. Epigenetic transgenerational actions of environmental factors in disease etiology. Trends Endocrinol. Metab. 2010, 21, 214-222. [CrossRef] [PubMed]

4. Dukes, J.S. Responses of invasive species to a changing climate and atmosphere. In Fifty Years of Invasion Ecology: The Legacy of Charles Elton; Richardson, D.M., Ed.; Wiley-Blackwell: Oxford, UK, 2011; pp. 345-357.

5. Richardson, D.M.; Pyšek, P. Fifty years of invasion ecology-the legacy of Charles Elton. Divers. Distrib. 2008, 14, 161-168. [CrossRef]

6. Ward, N.L.; Masters, G.J. Linking climate change and species invasion: An illustration using insect herbivores. Glob. Chang. Biol. 2007, 13, 1605-1615. [CrossRef]

7. Zhan, A.B.; Briski, E.; Bock, D.G.; Ghabooli, S.; MacIsaac, H.J. Ascidians as models for studying invasion success. Mar. Biol. 2015, 162, 2449-2470. [CrossRef]

8. Estoup, A.; Ravigné, V.; Hufbauer, R.; Vitalis, R.; Gautier, M.; Facon, B. Is there a genetic paradox of biological invasion? Annu. Rev. Ecol. Evol. Syst. 2016, 47, 51-72. [CrossRef]

9. Hawes, N.A.; Tremblay, L.A.; Pochon, X.; Dunphy, B.; Fidler, A.E.; Smith, K.F. Effects of temperature and salinity stress on DNA methylation in a highly invasive marine invertebrate, the colonial ascidian Didemnum vexillum. PeerJ 2018, 6, e5003. [CrossRef]

10. Pérez, J.E.; Nirchio, M.; Alfonsi, C.; Muñoz, C. The biology of invasions: The genetic adaptation paradox. Biol. Invasions 2006, 8, 1115-1121. [CrossRef]

11. Prentis, P.J.; Wilson, J.R.; Dormontt, E.E.; Richardson, D.M.; Lowe, A.J. Adaptive evolution in invasive species. Trends Plant Sci. 2008, 13, 288-294. [CrossRef]

12. Corona, D.F.; Tamkun, J.W. Multiple roles for ISWI in transcription, chromosome organization and DNA replication. BBA-Gene Struct. Expr. 2004, 1677, 113-119. [CrossRef] [PubMed]

13. Hopfner, K.-P.; Gerhold, C.-B.; Lakomek, K.; Wollmann, P. Swi2/Snf2 remodelers: Hybrid views on hybrid molecular machines. Curr. Opin. Struct. Biol. 2012, 22, 225-233. [CrossRef] [PubMed]

14. Cairns, B.R.; Kim, Y.-J.; Sayre, M.H.; Laurent, B.C.; Kornberg, R.D. A multisubunit complex containing the SWI1/ADR6, SWI2/SNF2, SWI3, SNF5, and SNF6 gene products isolated from yeast. Proc. Natl. Acad. Sci. USA 1994, 91, 1950-1954. [CrossRef]

15. Ito, T.; Bulger, M.; Pazin, M.J.; Kobayashi, R.; Kadonaga, J.T. ACF, an ISWI-containing and ATP-utilizing chromatin assembly and remodeling factor. Cell 1997, 90, 145-155. [CrossRef]

16. Shen, X.; Mizuguchi, G.; Hamiche, A.; Wu, C. A chromatin remodelling complex involved in transcription and DNA processing. Nature 2000, 406, 541. [CrossRef]

17. Erdel, F.; Rippe, K. Binding kinetics of human ISWI chromatin-remodelers to DNA repair sites elucidate their target location mechanism. Nucleus 2011, 2, 19873-19878. [CrossRef]

18. Bouazoune, K.; Brehm, A. ATP-dependent chromatin remodeling complexes in Drosophila. Chromosome Res. 2006, 14, 433-449. [CrossRef]

19. Toto, M.; D'Angelo, G.; Corona, D.F. Regulation of ISWI chromatin remodelling activity. Chromosoma 2014, 123, 91-102. [CrossRef]

20. Aydin, Ö.Z.; Marteijn, J.A.; Ribeiro-Silva, C.; Rodríguez López, A.; Wijgers, N.; Smeenk, G.; van Attikum, H.; Poot, R.A.; Vermeulen, W.; Lans, H. Human ISWI complexes are targeted by SMARCA5 ATPase and SLIDE domains to help resolve lesion-stalled transcription. Nucleic Acids Res. 2014, 42, 8473-8485. [CrossRef] 
21. Badenhorst, P.; Voas, M.; Rebay, I.; Wu, C. Biological functions of the ISWI chromatin remodeling complex NURF. Genes Dev. 2002, 16, 3186-3198. [CrossRef]

22. Tsukiyama, T.; Becker, P.B.; Wu, C. ATP-dependent nucleosome disruption at a heat-shock promoter mediated by binding of GAGA transcription factor. Nature 1994, 367, 525. [CrossRef]

23. Erkina, T.Y.; Zou, Y.; Freeling, S.; Vorobyev, V.; Erkine, A.M. Functional interplay between chromatin remodeling complexes RSC, SWI/SNF and ISWI in regulation of yeast heat shock genes. Nucleic Acids Res. 2009, 38, 1441-1449. [CrossRef]

24. Buszewicz, D.; Archacki, R.; Palusiński, A.; Kotliński, M.; Fogtman, A.; Iwanicka-Nowicka, R.; Sosnowska, K.; Kuciński, J.; Pupel, P.; Olędzki, J.; et al. HD2C histone deacetylase and a SWI/SNF chromatin remodelling complex interact and both are involved in mediating the heat stress response in Arabidopsis. Plant Cell Environ. 2016, 39, 2108-2122. [CrossRef]

25. Goldmark, J.P.; Fazzio, T.G.; Estep, P.W.; Church, G.M.; Tsukiyama, T. The Isw2 chromatin remodeling complex represses early meiotic genes upon recruitment by Ume6p. Cell 2000, 103, 423-433. [CrossRef]

26. Wagner, D. Chromatin regulation of plant development. Curr. Opin. Plant Biol. 2003, 6, 20-28. [CrossRef]

27. Collins, N.; Poot, R.A.; Kukimoto, I.; García-Jiménez, C.; Dellaire, G.; Varga-Weisz, P.D. An ACF1-ISWI chromatin-remodeling complex is required for DNA replication through heterochromatin. Nat. Genet. 2002, 32, 627. [CrossRef]

28. Brown, J.K.; Frohlich, D.; Rosell, R.C. The sweetpotato or silverleaf whiteflies: Biotypes of Bemisia tabaci or a species complex? Annu. Rev. Entomol. 1995, 40, 511-534. [CrossRef]

29. De Barro, P.J.; Liu, S.S.; Boykin, L.M.; Dinsdale, A.B. Bemisia tabaci: A statement of species status. Annu. Rev. Entomol. 2011, 56, 1-19. [CrossRef]

30. Liu, S.S.; Colvin, J.; De Barro, P.J. Species concepts as applied to the whitefly Bemisia tabaci systematics: How many species are there? J. Integr. Agric. 2012, 11, 176-186. [CrossRef]

31. Wang, X.W.; Yang, N.W. The Whitefly Bemisia tabaci (Gennadius). In Biological Invasions and Its Management in China; Wan, F.H., Jiang, M.X., Zhan, A.B., Eds.; Springer: Dordrecht, The Netherlands, 2017; pp. 159-182.

32. Broadbent, A.B.; Foottit, R.G.; Murphy, G.D. Sweetpotato whitefly Bemisia tabaci (Gennadius) (Homoptera: Aleyrodidae), a potential insect pest in Canada. Can. Entomol. 1989, 121, 1027-1028. [CrossRef]

33. Lee, C.E. Evolutionary genetics of invasive species. Trends Ecol. Evol. 2002, 17, 386-391. [CrossRef]

34. Wan, F.H.; Zhang, G.F.; Liu, S.S.; Luo, C.; Chu, D.; Zhang, Y.J.; Zang, L.S.; Jiu, M.; Lü, Z.C.; Cui, X.H. Invasive mechanism and management strategy of Bemisia tabaci (Gennadius) biotype B: Progress report of 973 Program on invasive alien species in China. Sci. China Ser. C Life Sci. 2009, 52, 88-95. [CrossRef]

35. Yu, H.; Wan, F.H.; Guo, J.Y. Different thermal tolerance and hsp gene expression in invasive and indigenous sibling species of Bemisia tabaci. Biol. Invasions 2012, 14, 1587-1595. [CrossRef]

36. Lü, Z.C.; Wan, F.H. Differential gene expression in whitefly (Bemisia tabaci) B-biotype females and males under heat-shock condition. Comp. Biochem. Physiol. Part D Genom. Proteom. 2008, 3, 257-262. [CrossRef]

37. Mahadav, A.; Kontsedalov, S.; Czosnek, H.; Ghanim, M. Thermotolerance and gene expression following heat stress in the whitefly Bemisia tabaci B and Q biotypes. Insect Biochem. Mol. Biol. 2009, 39, 668-676. [CrossRef]

38. Lü, Z.C.; Li, Q.; Liu, W.X.; Wan, F.H. Transient receptor potential is essential for high temperature tolerance in invasive Bemisia tabaci Middle East Asia minor 1 cryptic species. PLoS ONE 2014, 9, e108428. [CrossRef]

39. Dai, T.M.; Lü, Z.C.; Liu, W.X.; Wan, F.H.; Hong, X.Y. The homology gene BtDnmt1 is Essential for Temperature Tolerance in Invasive Bemisia tabaci Mediterranean Cryptic Species. Sci. Rep. 2017, 7, 3040. [CrossRef]

40. Dai, T.M.; Wang, Y.S.; Liu, W.X.; Lü, Z.C.; Wan, F.H. Thermal Discrimination and Transgenerational Temperature Response in Bemisia tabaci Mediterranean (Hemiptera: Aleyrodidae): Putative Involvement of the Thermo-Sensitive Receptor BtTRPA. Environ. Entomol. 2018, 47, 204-209. [CrossRef]

41. Lü, Z.C.; Wang, Y.M.; Zhu, S.G.; Yu, H.; Guo, J.Y.; Wan, F.H. Trade-offs between survival, longevity, and reproduction, and variation of survival tolerance in Mediterranean Bemisia tabaci after temperature stress. J. Insect Sci. (Oxford UK) 2014, 14, 124. [CrossRef]

42. Dai, T.M.; Lü, Z.C.; Wang, Y.S.; Liu, W.X.; Hong, X.Y.; Wan, F.H. Molecular characterizations of DNA methyltransferase 3 and its roles in temperature tolerance in the whitefly, Bemisia tabaci Mediterranean. Insect Mol. Biol. 2018, 27, 123-132. [CrossRef]

43. Chen, W.; Hasegawa, D.K.; Kaur, N.; Kliot, A.; Pinheiro, P.V.; Luan, J.; Stensmyr, M.C.; Zheng, Y.; Liu, W.; Sun, $\mathrm{H}$. The draft genome of whitefly Bemisia tabaci MEAM1, a global crop pest, provides novel insights into virus transmission, host adaptation, and insecticide resistance. BMC Biol. 2016, 14, 110. [CrossRef] 
44. Kumar, S.; Stecher, G.; Tamura, K. MEGA7: Molecular evolutionary genetics analysis version 7.0 for bigger datasets. Mol. Biol. Evol. 2016, 33, 1870-1874. [CrossRef]

45. Whelan, S.; Goldman, N. A general empirical model of protein evolution derived from multiple protein families using a maximum-likelihood approach. Mol. Biol. Evol. 2001, 18, 691-699. [CrossRef]

46. Dai, T.M.; Lü, Z.C.; Liu, W.X.; Wan, F.H. Selection and validation of reference genes for qRT-PCR analysis during biological invasions: The thermal adaptability of Bemisia tabaci MED. PLoS ONE 2017, 12, e0173821. [CrossRef]

47. Bowler, K.; Terblanche, J.S. Insect thermal tolerance: What is the role of ontogeny, ageing and senescence? Biol. Rev. 2008, 83, 339-355. [CrossRef]

48. Lü, Z.C.; Wan, F.H. Using double-stranded RNA to explore the role of heat shock protein genes in heat tolerance in Bemisia tabaci (Gennadius). J. Exp. Biol. 2011, 214, 764-769. [CrossRef]

49. Bubli, O.A.; Imasheva, A.G.; Loeschcke, V. Selection for knockdown resistance to heat in Drosophila melanogaster at high and low larval densities. Evolution 1998, 52, 619-625. [CrossRef]

50. Ma, F.Z.; Lü, Z.C.; Wang, R.; Wan, F.H. Heritability and evolutionary potential in thermal tolerance traits in the invasive Mediterranean cryptic species of Bemisia tabaci (Hemiptera: Aleyrodidae). PLoS ONE 2014, 9 , e103279. [CrossRef]

51. Mitchell, K.A.; Hoffmann, A.A. Thermal ramping rate influences evolutionary potential and species differences for upper thermal limits in Drosophila. Funct. Ecol. 2010, 24, 694-700. [CrossRef]

52. Gibert, P.; Moreteau, B.; Pétavy, G.; Karan, D.; David, J.R. Chill-coma tolerance, a major climatic adaptation among Drosophila species. Evolution 2001, 55, 1063-1068. [CrossRef]

53. Head, L.M.; Tang, X.; Hayley, S.E.; Goda, T.; Umezaki, Y.; Chang, E.C.; Leslie, J.R.; Fujiwara, M.; Garrity, P.A.; Hamada, F.N. The influence of light on temperature preference in Drosophila. Curr. Biol. 2015, 25, 1063-1068. [CrossRef]

54. Livak, K.J.; Schmittgen, T.D. Analysis of relative gene expression data using real-time quantitative PCR and the $2^{-\Delta \Delta C T}$ method. Methods 2001, 25, 402-408. [CrossRef]

55. Pfaffl, M.W. A new mathematical model for relative quantification in real-time RT-PCR. Nucleic Acids Res. 2001, 29, e45. [CrossRef]

56. Mathew, R.P.; Mishra, R.K.; Pandey, S.M. ISWI Chromatin Remodeling Complexes: Composition and Regulation perspectives. J. Sci. Res. 2018, 62, 133-145.

57. Grüne, T.; Brzeski, J.; Eberharter, A.; Clapier, C.R.; Corona, D.F.; Becker, P.B.; Müller, C.W. Crystal structure and functional analysis of a nucleosome recognition module of the remodeling factor ISWI. Mol. Cell 2003, 12, 449-460. [CrossRef]

58. Mueller-Planitz, F.; Klinker, H.; Ludwigsen, J.; Becker, P.B. The ATPase domain of ISWI is an autonomous nucleosome remodeling machine. Nat. Struct. Mol. Biol. 2013, 20, 82. [CrossRef]

59. De Barro, P.J.; Driver, F.; Trueman, J.W.; Curran, J. Phylogenetic relationships of world populations of Bemisia tabaci (Gennadius) using ribosomal ITS1. Mol. Phylogenet. Evol. 2000, 16, 29-36. [CrossRef]

60. Cui, X.H.; Wan, F.H.; Xie, M.; Liu, T. Effects of heat shock on survival and reproduction of two whitefly species, Trialeurodes vaporariorum and Bemisia tabaci biotype B. J. Insect Sci. (Oxford, UK) 2008, 8, 24. [CrossRef]

61. Muñoz-Valencia, V.; González-Obando, R.; Díaz, F. Rapid responses to a strong experimental selection for heat hardening in the invasive whitefly Bemisia tabaci MEAM 1. Entomol. Exp. Appl. 2016, 160, 147-155. [CrossRef]

62. Yu, H.; Wan, F.H. Cloning and expression of heat shock protein genes in two whitefly species in response to thermal stress. J. Appl. Entomol. 2009, 133, 602-614. [CrossRef]

63. Tsukiyama, T.; Daniel, C.; Tamkun, J.; Wu, C. ISWI, a member of the SW12/SNF2 ATPase family, encodes the $140 \mathrm{kDa}$ subunit of the nucleosome remodeling factor. Cell 1995, 83, 1021-1026. [CrossRef]

64. Shivaswamy, S.; Iyer, V.R. Stress-dependent dynamics of global chromatin remodeling in yeast: Dual role for SWI/SNF in the heat shock stress response. Mol. Cell. Biol. 2008, 28, 2221-2234. [CrossRef]

65. Huey, R.; Crill, W.; Kingsolver, J.; Weber, K. A method for rapid measurement of heat or cold resistance of small insects. Funct. Ecol. 1992, 6, 489-494. [CrossRef]

66. Goda, T.; Leslie, J.R.; Hamada, F.N. Design and analysis of temperature preference behavior and its circadian rhythm in Drosophila. JoVE-J. Vis. Exp. 2014, 83, e51097. [CrossRef]

67. Kaneko, H.; Head, L.M.; Ling, J.; Tang, X.; Liu, Y.; Hardin, P.E.; Emery, P.; Hamada, F.N. Circadian rhythm of temperature preference and its neural control in Drosophila. Curr. Biol. 2012, 22, 1851-1857. [CrossRef]

68. Fu, T.; Hull, J.; Yang, T.; Wang, G.R. Identification and functional characterization of four transient receptor potential ankyrin 1 variants in Apolygus lucorum (Meyer-Dür). Insect Mol. Biol. 2016, 25, 370-384. [CrossRef] 
69. Lee, Y.; Lee, Y.; Lee, J.; Bang, S.; Hyun, S.; Kang, J.; Hong, S.T.; Bae, E.; Kaang, B.-K.; Kim, J. Pyrexia is a new thermal transient receptor potential channel endowing tolerance to high temperatures in Drosophila melanogaster. Nat. Genet. 2005, 37, 305. [CrossRef]

70. Kinzner, M.T.; Kinzner, M.-C.; Kaufmann, R.; Hoffmann, A.A.; Arthofer, W.; Schlick-Steiner, B.C.; Steiner, F.M. Is temperature preference in the laboratory ecologically relevant for the field? The case of Drosophila nigrosparsa. Glob. Ecol. Conserv. 2019, 18, e00638. [CrossRef]

71. Dillon, M.E.; Liu, R.; Wang, G.; Huey, R.B. Disentangling thermal preference and the thermal dependence of movement in ectotherms. J. Therm. Biol. 2012, 37, 631-639. [CrossRef]

72. Huey, R.B.; Hertz, P.E.; Sinervo, B. Behavioral drive versus behavioral inertia in evolution: A null model approach. Am. Nat. 2003, 161, 357-366. [CrossRef]

73. MacLean, H.J.; Sørensen, J.G.; Kristensen, T.N.; Loeschcke, V.; Beedholm, K.; Kellermann, V.; Overgaard, J. Evolution and plasticity of thermal performance: An analysis of variation in thermal tolerance and fitness in 22 Drosophila species. Philos. Trans. R. Soc. B 2019, 374, 20180548. [CrossRef] [PubMed]

74. Stratman, R.; Markow, T. Resistance to thermal stress in desert Drosophila. Funct. Ecol. 1998, 12, 965-970. [CrossRef] (C) 2020 by the authors. Licensee MDPI, Basel, Switzerland. This article is an open access article distributed under the terms and conditions of the Creative Commons Attribution (CC BY) license (http://creativecommons.org/licenses/by/4.0/). 